https://doi.org/10.48009/2_iis_2014_231-241

Issues in Information Systems

Volume 15, Issue II, pp. 231-241, 2014

\title{
THE ROLE OF RFID IN THE SUPPLY-CHAIN: AN EDUCATIONAL CASE STUDY
}

\author{
Mohamed A. Lotfy, Regis University, mlotfy@regis.edu
}

\begin{abstract}
In today's global economy, quality management of the supply-chain is a critical factor for achieving a competitive advantage for the supply-chain partners and maximizing value for the customer. Radio frequency identification technology (RFID) is a proven technology that allows efficient tracking of products and their locations as they move through the supply-chain. This paper presents an educational case study that can be used in an undergraduate or graduate level supply-chain management course that addresses the role of RFID in the supply-chain and the effect of RFID on supply-chain quality management. The case study discusses the design and implementation of RFID solutions to manage the inventory and the supply-chain between a giant department store chain, and its suppliers and partners. A discussion that synthesizes the concepts explored in the case-study, the rationale for the learning objectives chosen, and the educational outcomes of the case study are provided.
\end{abstract}

Keywords: Information Management educational case study, Radio Frequency ID tags (RFID), Supply-chain management $(\mathrm{SCM})$

\section{INTRODUCTION}

The educational case study method and problem-based learning are proven strategies of effective methods of instruction [45]. Case studies are used in business, medicine, law, and information management to teach the complex, interdependent ideas essential in these fields and the skills needed in everyday practice $[29,45]$. Results from [22] indicate that case studies are effective in communicating the complex and multi-dimensional decisions inherit in information management. In information management education, contextualized case studies allow students to learn both content knowledge and problem solving skills simultaneously, thus enabling them to learn to think more effectively and develop needed problem-solving skills [25, 45]. The hypothetical case study approach helps students learn to recognize the important features of the information technology being studied, the range of problems to which a particular solution can be transferred and applied, and to abstract general principles from them. In information management case studies macro-context can help in managing the complexity of the presented problems [45]. Macro-contexts are designed with features that make complexity manageable, including using a story format, presentation, embedded data, and real-world accuracy [45].

A variety of learning strategies provide support for implementing information management case studies. Active learning is one of the most efficient forms of learning, since students learn better by doing rather than by hearing or seeing [11]. Information management case studies enhance the learning environment by allowing students to experience and develop several necessary business skills, such as building trust, risk-taking, respect for others, speaking skills, debating skills, self-confidence, group interaction, applying analytical techniques, as well as discovering the need for adequate preparation into a professional setting $[11,14,29]$. The case study approach allow the students develop critical thinking skills over time since these critical thinking skills can be learned through observing how others develop and express ideas [14]. Also, the case study approach allows the move from theoretical concepts to practical application without depending exclusively on one type of decision making model [14]. Information management case studies provide a way for creating realistic problem contexts that enable students to see the utility of knowledge and to understand the conditions for its use focusing on business data, active involvement, and assessment [25]. They allow for paralleling contemporary real world situations, team learning, and make students reflect on the lessons of the discussion [14].

The aim of this paper is to provide a hypothetical educational case study that can be used as a part of an undergraduate upper division or graduate supply-chain management course to teach the role of Radio Frequency ID 


\section{Issues in Information Systems \\ Volume 15, Issue II, pp. 231-241, 2014}

tags (RFID) and the effect of RFID on supply-chain quality management. The purpose of the case study is to introduce the student to the growing use and benefits of RFID tags in asset management, inventory control, supplychain visibility, and quality management of the supply-chain in today's business environment and helps the faculty to develop lesson plans and course notes that introduce and hone these concepts. The case discusses the design and implementation of RFID solutions (active and passive) to manage the inventory and the supply-chain between a giant department stores chain, and it suppliers and partners. The case study can be used in an online environment, classroom setting, or a blended format. The provided case study will be used in an MBA strategic management course starting the fall term 2014.

The remainder of this paper is organized as follows: part two of this paper provides a short review of RFID tags and their use in the supply-chain. Part three provides the educational RFID case study. Part four provides an analysis and discussion of the case study, provides information management faculty with an overview of the case study, the educational objectives and goals, and the outcomes of the educational study case. Part five provides a summary of the case study approach in information management education and concluding remarks.

\section{THE USE OF RFID IN SUPPLY-CHAIN OPERATIONS AND MANAGEMENT}

For an organization to provide goods and services, it has to rely on suppliers and partners to obtain needed production materials and distributers to deliver the products and/or services to the customer and the customer's customer. This network of manufactures and service providers that work and collaborate together to transform raw materials to a final product or service is called a supply-chain. Organizations in the supply-chain are linked together through physical, informational, and monetary flows [30].

Supply-chain management (SCM) is more than integrated logistics. According to [31], today SCM consists of five components which include: alliances with key partners, lean manufacturing, lean logistics, integration of key business processes, and information technology with the main objective that all components of the supply-chain add value to the customer. SCM involves integration and collaboration in product development, demand management, planning and forecasting, order fulfillment, and effective and efficient customer service [32]. SCM includes planning, implementing, and controlling the supply-chain to lower the inventory and stock outs cost (managing capacity and inventory), improving the product or service design and quality (managing production and quality), improving the delivery speed of products and services (managing logistics), and providing information integration and visibility throughout the supply-chain (information management) [9, 31, 36, 46, 47]. The availability of fast, accurate, relevant, and accessible information is critical for supply-chain management performance [32]. In today's global economy, quality management of the supply-chain is a critical factor for achieving a competitive advantage for the supply-chain partners and maximizing value to the customer [7, 9]. A main goal of SCM should be the optimization of the business process flow among the elements of the supply-chain through the creation of visibility across the supply-chain [39].

The use of information technology, IT, is a critical factor and enabler of establishing an efficient and effective supply-chain $[32,34]$. The IT capabilities are used to conduct business transactions, ordering and funds transfer through the use of electronic data interchange (EDI), information sharing and visibility, and real-time inventory tracking in the supply-chain $[15,34]$. Administrative and operational efficiency in addition to cost reductions can be achieved through efficient transaction processing, inventory tracking, and process linkage across the supply-chain $[36,46,47]$. Through the IT capabilities, knowledge (skills and expertise) leverage can be utilized by capitalizing on the competencies and expertise of the partners and participants in the supply-chain [7,9]. Coordination through the supply-chain and internal streamlined IT infrastructure are critical to create a differential business advantage that is flexible and responsive to the diverse and changing customer needs [7, 9, 20, 32, 39, 41].

Since the late 1990s, Radio frequency identification (RFID) tags have been used in logistics to track and monitor pallets $[36,46,47]$. Due to the advancements in RFID tags design and the availability of low-cost RFID tags, RFID technology has been used and implemented in supply-chains and used to provide effective and efficient management 


\section{Issues in Information Systems \\ Volume 15, Issue II, pp. 231-241, 2014}

of the supply-chain [4, 5]. An RFID tag is a chip that holds an electronic product code (EPC) which is attached to or imbedded in the product $[3,20,38]$. The RFID tag transmits its data wirelessly to a reader which communicates the captured data to a middleware system through which the product can be identified and located [3, 20, 44]. RFID tags can be either passive or active. While an active RFID tag contains a tiny battery that enables the tag to transmit its EPC to the reader, a passive RFID tag is energized through the radio signals from the reader [3,20]. Active RFID tags have a longer range (about 100 feet or more), can perform independent monitoring and control, and are capable of initiating communications with the readers. Passive RFID tags are smaller and cheaper than active RFID tags, have a shorter range but can be read for up to twenty years [3, 20, 26, 42].

RFID technology offers several improvements over earlier technologies such as barcodes and magnetic stripe cards. RFID tags do not require a direct line-of sight to be read by the reader [28]. An RFID tag stores more information than barcodes and magnetic stripes [20,38]. Also, RFID tags enable the addition of new information when necessary. In addition, RFID readers can read multiple RFID tags simultaneously and collect detailed information in one pass without human intervention $[18,36,38,44]$.

Due to RFID technology ability to track and monitor, it has been used and implemented in supply-chains and used in supply-chain management. Since RFID enables the integration of inventory and logistics systems in supply-chains, RFID usage provides substantial cost cuts in supply-chain operations through the elimination of delivery lag time, the determination of point of origin, efficient tracking, and inventory visibility across the supply-chain $[6,21,23,27$, $39,46,47]$. The RFID technology provides better supply-chain management through streamlining supply-chain processes, automating just-in-time product shipment, enabling business intelligence, and better interaction with the customer [21, 30, 36, 44]. RFID tags are used in monitoring and tracking goods, monitoring product quality, authenticating the product, enabling wireless payment systems, measuring systems availability, and control and security $[4,5,6,21,32,37,38,44]$. While hospitals are using RFID in the wrist bands of patients and babies, and are tagging expensive medical equipment using active RFID tags, pharmaceutical companies are expanding the use of RFID tags to reduce drug counterfeiting [1, 19, 24, 36, 46].

RFID allows manufacturers and suppliers better production tracking (raw materials tracking, production inventory tracking, and assembly status tracking), quality control throughout production, and provides supply and production continuity through continuous equipment monitoring to reduce equipment downtime $[6,7,8,17,35,40]$. Distributers and logistics mangers can achieve better material handling, better space utilization, and better asset management due to RFID implementation in the supply-chain [17, 23, 26, 27]. The RFID benefits for retailers affect all members of the supply chain and leads to maximization of value to the customer due to stock outs reduction, better customer service, better after sales service, and lower inventory [30, 32, 38, 40].

RFID tags are used in libraries to speed up checkouts, keeping collections in order, providing better control against theft, managing non returns, and misfiling of a library's assets [33]. Also, RFID tags are used in perishable food and grocery supply-chains to improve traceability, information accuracy, and operation efficiency [13, 21, 43]. The use of RFID resulted in labor costs, increased delivery speed, greater responsiveness to customer needs, and better product quality control [13, 21, 23, 27, 43]. Through the use of RFID to manage the supply-chain management the following benefits across the whole supply-chain could be achieved which include: reduced shrinkage due to misplaced items, spoilage, and shoplifting; reduced material handling due to reduced receiving time, reduced loading and unloading time, and reduced human errors; increased data accuracy and improved information sharing which leads to faster response to unplanned events [13, 21, 36, 38, 43].

Despite the benefits of the RFID technology in the supply-chain and its impact on SCM, there are many challenges that might face the supply-chain partners when they are implementing the RFID technology that might cause it not to yield the perceived benefits in the supply-chain. The challenges that might impact the growth of RFID include: standardization, technology maturation, implementation costs, and security and privacy issues $[2,18,39]$. Due to the wireless nature of the RFID technology some implementations might suffer from interference, reflection, and refraction in warehouses which leads to a decrease in identification rates [28]. Also, supply-chain partners might 


\section{Issues in Information Systems \\ Volume 15, Issue II, pp. 231-241, 2014}

suffer from interoperability between the RFID systems due to the lack of consistent UHF frequency spectrum allocation for RFID and patent challenges [2, 28]. Other RFID implementation challenges are the conversion costs from barcode to EPC and other customization costs to make the manufacturing and production platforms RFID compatible [39].

Another big challenge for successful RFID implementations across the supply-chain is the cost of integrating different IT infrastructure and systems. The IT challenges include: reader integration into the IT middleware infrastructure, reduction of collisions while reading RFID tags, RFID data filtering and aggregation, RFID data dissemination to all supply-chain partners, and RFID data warehousing and storage $[10,16,39]$. Securing the wireless RFID data and the collected and stored RFID data is another challenge for the supply-chain partners [2, 18, 38].

Security and privacy issues are two of the major concerns that are limiting the widespread implementation of RFID technology across supply-chains. The availability of databases generated from the collected RFID data across the supply-chain raises important security considerations related to the confidentiality and integrity of the collected data [38]. Also, privacy concerns from the ability of RFID tags to be used in tracking an individual's movements and their purchasing and product using habits are causing major retailers to rethink and slowdown their RFID adoption plans $[2,18,44]$.

\section{AN RFID EDUCATIONAL CASE STUDY}

Malot, a giant department stores chain, started in 1959 as a small department store in the city of Denver, Colorado. Today Malot chain consists of 782 stores covering twenty states. In recent years, Malot was losing money due to lost and misplaced pallets in the supply-chain. The misplaced products in the stores were causing the customers to feel that Malot was not taking customer service seriously. Recent surveys of Malot customers were showing the increased frustration of the perceived poor customer service, long checkout lines, and the unavailability of some of the high in demand products.

Since Malot had about 1,500 high-end denim items, hoodies, leather jackets, and other clothing aimed at its young clientele, shoplifting was an increasing headache for store management and resulted in additional loss of revenue. In 2004, Malot embarked on a massive project to implement Radio Frequency ID tags (RFID) in its warehouses and stores to RFID tag high-value, high-profit, and high-turnover products. In addition to RFID products in the stores, Malot was working with its manufactures, suppliers and partners to RFID tag the supply-chain which allowed for better asset management, inventory control, visibility in the supply-chain, and provided value for Malot customer.

Overview/Analysis

A RFID tag is a chip, which holds an electronic product code (EPC), which is attached to or imbedded in the product. The tag transmits its data wirelessly to a reader that communicates the captured data to a computer. Through the use of a middleware program, the product can be identified and located. RFID tags can be either passive or active. While an active RFID tag contains a tiny battery that enables the tag to transmit its EPC to the reader, a passive RFID tag is energized through the radio signals from the reader. Active RFID tags have longer range (about 100 feet or more), which can perform independent monitoring and control, and are capable of initiating communications with the readers. Despite Passive RFID tags have a shorter range they can be read for up to twenty years. Passive RFID tags are smaller and cheaper than active RFID tags.

In 2008, Malot made a business decision to use passive RFID tags to tag high-value, high-profit, and high-turnover products. This decision required the development of a three year implementation plan to install RFID tag readers and the required IT infrastructure in all the 782 stores. To enable the RFID transition and the successful implementation of the plan, Malot senior administration managed to convince the product manufacturers, suppliers, and partners to start delivering RFID tagged merchandise by the end of 2009. As an incentive to its manufactures, suppliers, and partners, Malot agreed to cover half of the RFID tags cost. 


\section{Issues in Information Systems \\ Volume 15, Issue II, pp. 231-241, 2014}

Malot's decision to split the 25 cents RFID tags cost was due to a detailed analysis by the financial team which showed that the use of the RFID tags to tag high-value, high-profit, and high-turnover products will improve theft protection which will result in reduced product costs. The report predicted increased sales revenue due to increased sales volume from the reduced product costs, from the better stocking and availability of the products, and better customer service.

By the end of 2010, end of the first year of RFID tags usage, Malot revenues increased by $10 \%$ which convinced senior management to move ahead with the use of active RFID tags to tag pallets and bins to provide better management of the supply-chain. Senior management asked the VP of Logistics and Asset Management to investigate the use of active RFID tags in the supply-chain. Malot's senior management believes that better asset tracking and inventory management will convince its manufactures, supplier, and partners to move along and support the automation of the supply-chain through the use of active RFID.

In February 2011, Malot's VP of Logistics and Asset Management submitted a report to senior management that showed that significant savings due to the automation of the supply-chain can be achieved. Malot's manufacturers, suppliers, and partners also saw the same benefits and agreed to work with Malot to automate the supply-chain. Plans were developed to automate the supply-chain by the end of 2012.

\section{Case Problems}

The use of active RFID tags in the supply-chain

Malot Senior administration had a long meeting discussing to move the active RFID tagging of the supplychain. The following are parts of the transcript of the meeting:

Malot's CFO: "I totally agree with the move to use active RFID tags in the supply-chain. The ability to pin down the location of a specific item in the supply-chain has obvious benefits to our customer, to us, our manufactures, and our suppliers and partners; don't you agree?"

Malot's VP of Logistics and Asset Management: "With RFID, deliveries can be registered before a pallet is even unpacked which will allow us to better track and manage our inventory. In addition, RFID tags will enable our fork-lift drivers, as they driving through the dock door, to have the RFID tags read off the pallet automatically to our inventory system."

Malot's CFO: "I agree, up till now, it was not economically viable to look at retail shrinkage very closely. Let's not forget that the savings can be substantial which will definitely result in increased revenues." Malot's CIO: "I understand where all of you are coming from. However, there is not yet full global agreement on the standards of active RFID so how this will be achieved? Also, there is a need to integrate RFID with existing infrastructure and IT to turn on RFID event into a viable business solution." Malot's CEO: "The business case is not simple folks; it will require us to encourage our partners to move along with us. Active tagging is still not cheap and requires process changes in the supply-chain, which might slowly add up. Let's not forget there are also politics within an organization that need to be dealt with before we move on."

1. You are the VP of Logistics and Asset Management at Malot, write a five page report to senior management about your recommendations regarding the use of active RFID tags in the supply-chain. The report should have a one page executive summary identifying the benefits, opportunities, and risks of using RFID to automate the supply-chain. Also, the report has to have, as an appendix, a one page ROI analysis Excel spreadsheet.

2. You will present your findings to Malot senior management (the class); prepare a short presentation of your report. In the presentation summarize your recommendations, provide a rationale for the recommendations, and include a cost/benefit analysis slide.

Benefits of Automating the Supply-Chain through the Use of Active RFID Tags 


\section{Issues in Information Systems \\ Volume 15, Issue II, pp. 231-241, 2014}

Despite the benefits of RFID tagging in the supply-chain, getting companies to implement it is not always easy. Companies like Malot have the muscle to encourage a little compliance among its suppliers, but given that this costs suppliers money, why would they do it if they don't have to?

As a group discuss the above paragraph and develop a list of benefits for the suppliers and partners to join Malot in automating the supply-chain. Identify the risks that Malot might face if some of the suppliers and partners don't want to incur the additional costs of using RFID. Each group has to come up with at least five benefits and risks. Each group will present their list of benefits to the other groups and provide a rationale of why Malot's suppliers and partners should join in automating the supply-chain and what risks they might face if they don't.

The Usage of RFID Tags to Provide Better Customer Service and Ethical/Privacy Ramifications Malot used RFID tags to tag high-end denim items, hoodies, leather jackets, and other clothing aimed at its young clientele. The use of RFID tags led to the speed up of the checkout process and reduced shoplifting. Malot's VP of Marketing wants to install RFID readers in the dressing rooms. When a customer enters the fitting cubicle to try on the clothes, the reader reads the EPCs and displays relevant information on a touch-screen monitor in the cubicle, such as a biography of the clothes designer, or photos of celebrities wearing that item.

Malot's VP of Marketing plans to create an RFID-based Malot loyalty card for selected customers. When these customers walk in, the RFID system will identity them and call up their complete buying history and preferences. The sales staff in the vicinity of the customer will be notified, through a handheld device, that a valued customer is in their area and the customer location identified on the device. The handheld device will show suggested merchandise and discounts that they can share and offer the customer.

As a preferred customer of Malot you requested a Malot loyalty card. After a couple of visits to Malot, you told your friends about the new reduced pricing of the merchandize, the new touch screens in the fitting rooms, and how Malot's customer service improved. One of your friends told you about how Malot is using RFID, through the loyalty cards, to identify your preferences, your purchase history, where you are in the store, and provide targeted promotions and suggestions that matches your preferences.

Write a three-page paper discussing the following questions:

1. Does the Malot loyalty card add value to you?

2. Is the Malot loyalty card an infringement on your privacy?

3. Is Malot's use of the RFID system in the store ethical? Legal?

4. Do the benefits of customized promotions and better customer service outweigh your privacy concerns?

\section{DISCUSSION OF THE EDUCATIONAL CASE}

The educational case study addresses the role of RFID in the supply-chain and the effect of RFID on supply-chain quality management. The purpose of the case study is to introduce the student to the growing use and benefits of RFID tags in asset management, inventory control, supply-chain visibility, and quality management of the supplychain in today's business environment. The case study discusses the design and implementation of RFID solutions (active and passive) to manage the inventory and the supply-chain between a giant department stores chain, and its suppliers and partners.

The case study exposes the student to the different uses of RFID tags in the business and the supply-chain, some of the future uses of RFID tags, and some of the ethical and privacy issues that might arise. At the end of the case study, students should have a better understanding of the following issues:

1. The infrastructure of RFID technology and its use in the business.

2. The role of supply-chain information systems in supply-chain management.

3. The effect of RFID on supply-chain QM

4. The value added benefits to the customer through the use of RFID tagging. 


\section{Issues in Information Systems \\ Volume 15, Issue II, pp. 231-241, 2014}

5. The ethical issues due to the use of RFID tags in retail to improve customer service.

6. The privacy issues due to the use of RFID tags in retail to improve customer service.

The case study introduces the student to the use of active RFID tags in the supply-chain, to understand the benefits that could be achieved from automating and quality managing the supply-chain through the use of RFID tags, and how RFID can be used to provide better customer service, and the ethical and privacy issues that might stem from the use of RFID in the supply-chain. The case study activities serve to solidify concept mastery and promote discussion among class members. The student activities are a combination of writing, group discussions, and presentations emphasizing role-playing as business executives, project managers, business analysts, and customers.

The first writing assignment is an executive summary and a five-page business report identifying the benefits, opportunities, and risks of using RFID to automate the supply-chain that allow the student to hone their business writing skills. Each student is required to develop a presentation and presenting it to the class discussing the recommendations for RFID usage and providing a rationale for the recommendations including a cost/benefit analysis slide. The aim of the presentations is to enhance the student business communication skills and oral communication delivery mechanisms. The group discussion activities are used to enhance group communication skills and allow the students to work in teams.

The educational case supplemental readings and resources reinforce the concepts about the RFID role in supplychain management. The concepts of quality management of the supply-chain as a critical factor for achieving a competitive advantage for the supply-chain partners should be explored and stressed. The different activities in supply-chain management should be discussed and reflected upon in the class and in the case activities. The benefits of the RFID technology in the supply-chain and its impact on supply-chain management, the challenges that might face the supply-chain partners when they are implementing the RFID technology, and the causes that might cause the RFID implementation will not yield the perceived benefits in the supply-chain need to be enforced. The advantages of using RFID in the supply-chain from integration of inventory and logistics systems in supplychains, the substantial cost cuts in supply-chain operations through the elimination of delivery lag time, efficient tracking, and inventory visibility across the supply-chain should be presented, discussed, and reinforced. The role RFID technology plays in providing better supply-chain management through streamlining supply-chain processes, monitoring and tracking of goods, monitoring product quality, authenticating the product, and control and security should be stressed and emphasized throughout the class. Also, supply-chain phenomena like shrinkage and bullwhip effects are introduced and the impact of RFID usage on reducing these phenomena need to be discussed.

The case study allows the student to understand that a successful RFID technology deployment involves changes to the organization, its business processes, and the business processes across the supply-chain. These changes in the supply chain could impact the whole supply-chain. Organizations in the supply should not make business decisions driven by their own benefits but should work and collaborate with the suppliers, manufacturers, and partners to identify the business opportunities that could lead achieving a competitive advantage for the whole supply-chain.

The case study exposes that security and privacy issues that could impact the widespread implementation of RFID technology across the supply-chain. Customer's concerns regarding the security considerations related to the confidentiality and integrity of the collected data and privacy concerns from the ability of RFID tags to be used in tracking the customer movements and purchasing and product using habits need to be investigated. The case study demonstrates the impact RFID might have on the return of the investment due to the different ethical implications and privacy issues raised due to the use of RFID tags in consumer products. The case study raises the student awareness about the ethical impacts of RFID tagging, including privacy issues, that should be taken into consideration by RFID tags producers and businesses planning to implement RFID.

In class, online, or blended faculty should discuss the design and implementation of RFID solutions (active and passive) to manage the inventory and the supply-chain. The faculty should integrate the different uses of RFID tags in the business and the supply-chain, the future uses of RFID tags, and the ethical and privacy issues that might arise from RFID usage in the discussions and handouts. The faculty should develop assessment rubrics that access that 


\section{Issues in Information Systems \\ Volume 15, Issue II, pp. 231-241, 2014}

achievement of the case study outcomes. The faculty needs to incorporate brainstorming, group discussions, and role play activities in their facilitation plan to can help the students identify the major issues raised by the case study. The facilitator can use the discussions to identify, analyze, and raise the awareness of the different uses of RFID to provide quality management of the supply-chain and the ethical and privacy issues of RFID. The facilitator can use scenarios, team projects, term papers, etc. to enable the student to perform an in-depth study of the issues raised by the case study which can include ROI analysis, SWOT analysis, and risk analysis. The faculty should plan additional activities and discussion questions that could be used to enhance the educational experience.

The faculty needs to provide an adequate set of articles to accompany the case study that need to be used by the students as supplemental readings to increase their understanding of the issues raised by the case study. The articles should be a selected group of RFID literature that provides an in-depth understanding of the RFID technology and its use in SCM. The articles should provide a better understanding of the effect of RFID implementations on the ROI and the ethical implications emanating from RFID usage that might reduce the total ROI. The articles need to stress the fact that corporations should take into consideration RFID privacy issues and be more socially responsible regarding their RFID implementations. The articles need to provide a good understanding of the technology infrastructure required for efficient RFID implementations and the RFID middleware layer and its services, the RFID technology data lifecycle, application logic, business processes, and management issues in supply-chain RFID implementations, and the impact of the RFID technology on the organization and the business processes. The articles should provide different examples of RFID implementations in hospitals, pharmaceutical industry, and retail etc. The articles can be used to initiate healthy discussions and debates regarding the RFID use and the ethical and privacy concerns which enhance the student understanding and enable the achievement of the case study objectives.

\section{CONCLUSIONS}

RFID technology is a proven technology that allows efficient tracking of products and their locations as they move through the supply-chain. RFID is a relatively low cost technology that can improve supply-chain visibility and can drastically cut operation costs. The technology also has enormous potential for enabling quality management across the supply-chain and adding value to it.

The paper provides a hypothetical educational case study that can be used as a part of an undergraduate upper division or graduate supply-chain management course to teach the role of Radio Frequency ID tags (RFID) and the effect of RFID on supply-chain quality management. The case study focuses on the use of RFID in providing quality management of the supply-chain and how organizations can achieve and sustain the competitive advantage through total quality management and business process improvement using RFID enabled supply-chains. The case study helps students to examine and review the RFID technology, its implementation across the supply-chain, and the organizational and business process impacts on the IT infrastructure for successful RFID implementations. The case study exposes the students to the pros, cons, and the potential returns of implementation (ROI), the ethical implications on the society and the business settings, and the consideration of the true costs when evaluating RFID solutions. Also, it allow the student to understand the different ethical implications and privacy issues raised due to the use of RFID tags in consumer products and their possible effects on ROI. The case study exposes the students to the different IT manager roles in RFID enables supply chains.

The paper provides a detailed literature review that could help faculty teaching IT management, RFID, supply-chain management courses to identify additional readings that expose the students to current RFID supply-chain management trends, research, and literature. A limitation of the case study is that it did not investigate the newer generation of readable/writable RFID tags and their usage. Also, the security ramifications of the usage of RFID tags and possibility of data theft were not discussed. These issues can be easily added by the faculty to the case study. In developing information management case studies the domain knowledge should be presented. Faculty who will be writing their own case studies should employ techniques and strategies to reduce the complexity of problem solution. The case study questions should allow students to reflect on the solutions, help students develop a more coherent understanding of information management, and allow the transfer of the knowledge. Case study problem 


\section{Issues in Information Systems \\ Volume 15, Issue II, pp. 231-241, 2014}

solutions should be explored jointly and students encouraged to form a community of scholars. The case study presented in this paper will be used in a strategic management MBA course offered in the fall term of 2014. Results from the use of the case study in an actual class setting (success rates, student satisfaction, etc.) will be shared in a future publication as well as lessons learned, any additional activities, and questions that will emerge from the use of the case study in the class that will lead to an increase in the level of active and team learning will be analyzed and presented.

\section{REFERENCES}

1. Anshel, M., \& Levitan, S. (2007). Reducing medical errors using secure RFID technology. ACM SIGCSE Bulletin, 39(2), 157-159. doi:10.1145/1272848.1272900

2. Barut, M., Brown, R., Freund, N., May, J., \& Reinhart, E. (2006). RFID and corporate responsibility: Hidden costs in RFID implementation. Business and Society Review, 111(3), 287-303. doi:10.1111/j.14678594.2006.00273.x

3. Fosso Wamba, S., Lefebvre, L. A., Bendavid, Y., \& Lefebvre, É. (2008). Exploring the impact of RFID technology and the EPC network on mobile B2B eCommerce: A case study in the retail industry. International Journal of Production Economics, 112(2), 614-629. doi:10.1016/j.ijpe.2007.05.010

4. Department of Commerce. (2005, April). Radio frequency identification. Opportunities and challenges in implementation. Washington, D.C.: The department of Commerce's RFID Working Group.

5. Dolgui, A., \& Proth, J. M. (2010). Radio-frequency identification (RFID): Technology and applications. Supply Chain Engineering: Useful Methods and Techniques, 163-194. doi:10.1007/978-1-84996-017-5_5

6. Ergen, E., Akinci, B., East, B., \& Kirby, J. (2007). Tracking components and maintenance history within a facility utilizing radio frequency identification technology. Journal of Computing in Civil Engineering, 21(1), 11-20. doi:10.1061/(ASCE)0887-3801(2007)21:1(11).

7. Erickson, G. S., \& Kelly, E. P. (2007). Building competitive advantage with radio frequency identification tags. An International Business Journal incorporating Journal of Global Competitiveness, 17(1/2), 36-47. doi:10.1108/10595420710816597

8. Ferguson, G., (2002, June) Have your Objects Call My Objects. Harvard Business Review, 138-144.

9. Fish, L. A., \& Forrest, W. C. (2006). The 7 success factors of RFID. Supply Chain Management Review, 10(6), 26-32.

10. Floerkemeier, C., \& Lampe, M. (2005). RFID middleware design: Addressing application requirements and RFID constraints. Proceedings of the 2005 joint conference on Smart objects and ambient intelligence: innovative context-aware services: usages and technologies, 219-224. Grenoble, France. doi:10.1145/1107548.1107603

11. Foran, J. (2001). The case method and the interactive classroom. Thought and Action, 19(1), 41-50.

12. Goel, R. (2007). Managing RFID consumer privacy and implementation barriers. Information Systems Security, 16(4), 217-223. doi:10.1080/10658980701576396

13. Grocery Manufacturers of America. (2004). A balanced perspective: EPC/RFID implementation in the CPG industry. Prepared by IBM \& A.T. Kearney for the Grocery Manufacturers of America.

14. Herreid, C. F., \& Schiller, N. A. (2013). Case studies and the flipped classroom. Journal of College Science Teaching, 42(5), 62-66.

15. Imburgia, M. J. (2006, June). The role of RFID within EDI: building a competitive advantage in the supply chain. In Service Operations and Logistics, and Informatics, 2006. SOLI'06. IEEE International Conference on (pp. 1047-1052). IEEE.

16. Ivanov, D., Dolgui, A., \& Sokolov, B. (2013). Multi-disciplinary analysis of interfaces" Supply Chain Event Management-RFID-control theory". International Journal of Integrated Supply Management, 8(1), 52-66. doi:10.1504/IJISM.2013.055071

17. Jaseiskis, E. J., \& Ei-Misalami, T. (2003). Implementing radio frequency identification in the construction process. Journal of Construction Engineering \& Management, 129(6), 680-688. 


\section{Issues in Information Systems \\ Volume 15, Issue II, pp. 231-241, 2014}

18. Juels, A., Rivest, R. L., \& Szydlo, M. (2003, October). The blocker tag: selective blocking of RFID tags for consumer privacy. In Proceedings of the 10th ACM conference on Computer and communications security (pp. 103-111). ACM. doi:10.1145/948109.948126

19. Kumar, S., Swanson, E., \& Tran, T. (2009). RFID in the healthcare supply chain: usage and application. International Journal of Health Care Quality Assurance, 22(1), 67-81. doi:10.1108/09526860910927961

20. Kumar, K. (2001). Technology for supporting supply chain management: introduction. Communications of the $A C M, 44(6)$, 58-61. doi:10.1145/376134.376165

21. Li, D., Kehoe, D., \& Drake, P. (2006). Dynamic planning with a wireless product identification technology in food supply chains. International Journal of Advanced Manufacturing Technology, 30, 938-944. doi:10.1007/s00170-005-0066-1

22. Linn, M. C., \& Clancy, M. J. (1992). The case for case studies of programming problems. Communications of the ACM, 35(3), 121-132. doi:10.1145/131295.131301

23. Loomba, A. P., \& Nakashima, K. (2012). Enhancing value in reverse supply chains by sorting before product recovery. Production Planning \& Control, 23(2-3), 205-215. doi:10.1080/09537287.2011.591652

24. Malykhina, E. (2006, July 19). Non retail businesses take lead with item-level RFID. Retrieved from www.informationweek.com.

25. Mamei, M., Menezes, R., Tolksdorf, R., \& Zambonelli, F. (2006). Case studies for self-organization in computer science. Journal of Systems Architecture, 52(8), 443-460. doi:10.1016/j.sysarc.2006.02.002

26. Niederman, F., Mathieu, R. G., Morley, R., \& Kwon, I. K. (2007). Examining RFID applications in supply chain management. Communications of the ACM, 50(7), 93-101. doi:10.1145/1272516.1272520

27. Ondemir, O., Ilgin, M. A., \& Gupta, S. M. (2012). Optimal end-of-life management in closed-loop supply chains using RFID and sensors. Industrial Informatics, IEEE Transactions on, 8(3), 719-728. doi:0.1109/TII.2011.2166767

28. Penttilä, K., Keskilammi, M., Sydänheimo, L., \& Kivikoski, M. (2006). Radio frequency technology for automated manufacturing and logistics control. Part 2: RFID antenna utilisation in industrial applications. International Journal of Advanced Manufacturing Technology, 31(1/2), 116-124. doi:10.1007/s00170-0050174-y

29. Rasmussen, E. A., \& Sørheim, R. (2006). Action-based entrepreneurship education. Technovation, 26(2), 185194. doi:10.1016/j.technovation.2005.06.012

30. Roussos, G. (2006, March). Enabling RFID in retail. Computer, 39(3), 25-30. doi: 10.1109/MC.2006.88.

31. Russell, S. H. (2007). Supply chain management: More than integrated logistics. Air Force Journal of Logistics, 31(2), 56-63.

32. Sarac, A., Absi, N., \& Dauzère-Pérès, S. (2010). A literature review on the impact of RFID technologies on supply chain management. International Journal of Production Economics, 128(1), 77-95. doi.org/10.1016/j.ijpe.2010.07.039

33. Sing, J., Brar, N., \& Fong, C. (2013). The state of RFID applications in libraries. Information technology and libraries, 25(1), 24-32. doi: 10.6017/ital.v25i1.3326

34. Singh, N. (2003). Emerging technologies to support supply chain management. Communications of the ACM, 46(9), 243-247. doi:10.1145/903893.903943

35. Song, J., Haas, C. T., \& Caldas, C. H. (2006). Tracking the location of materials on construction job sites. Journal of Construction Engineering \& Management, 132(9), 911-918. doi:10.1061/(ASCE)07339364(2006)132:9(911)

36. Symonds, J., \& Parry, D. (2008). Using RFID to track and trace high value products: The case of city healthcare. Journal of Cases on Information Technology (JCIT), 10(1), 1-13. doi:10.4018/jcit.2008010101

37. Tajima, M. (2007). Strategic value of RFID in supply chain management. Journal of Purchasing and Supply Management, 13(4), 261-273. doi:10.1016/j.pursup.2007.11.001

38. Thiesse, F., \& Condea, C. (2009). RFID data sharing in supply chains: what is the value of the EPC network?. International Journal of Electronic Business, 7(1), 21-43. doi:10.1504/IJEB.2009.023607

39. Trappey, C. V., Trappey, A. J. C., Lin, G. Y. P., Liu, C. S., \& Lee, W. T. (2007). Business and logistics hub integration to facilitate global supply chain linkage. Proceedings of the Institution of Mechanical Engineers -Part B -- Engineering Manufacture, 221(7), 1221-1233. doi:10.1243/09544054JEM753 


\section{Issues in Information Systems}

Volume 15, Issue II, pp. 231-241, 2014

40. Visich, J. K., Li, S., \& Khumawala, B. M. (2007). Enhancing product recovery value in closed-loop supply chains with RFID. Journal of Managerial Issues, 19(3), 436-452.

41. Visich, J. K., Li, S., Khumawala, B. M., \& Reyes, P. M. (2009). Empirical evidence of RFID impacts on supply chain performance. International Journal of Operations \& Production Management, 29(12), 1290-1315. doi:10.1108/01443570911006009

42. Wamba, S., Lefebvre, L., \& Lefebvre, E. (2006). Enabling intelligent B-to-B eCommerce supply chain management using RFID and the EPC network: a case study in the retail industry. Proceedings of the 8th international conference on Electronic commerce: The new e-commerce: innovations for conquering current barriers, obstacles and limitations to conducting successful business on the internet, 156, 281-288. Fredericton, New Brunswick, Canada. doi:10.1145/1151454.1151502

43. Wang, L., Kwok, S. K., \& Ip, W. H. (2010). A radio frequency identification and sensor-based system for the transportation of food. Journal of food engineering, 101(1), 120-129. doi:10.1016/j.jfoodeng.2010.06.020

44. Weinstein, R. (2005, May/June). RFID: A technical overview and its application to the enterprise. IT Professional, 7(3), 27-33. doi:10.1109/MITP.2005.69

45. Williams, S. M. (1992). Putting case-based instruction into context: Examples from legal and medical education. The Journal of the Learning Sciences, 2(4), 367-427. doi:10.1207/s15327809j1s0204_2

46. Xu, J., Jiang, W., Feng, G., \& Tian, J. (2012). Comparing improvement strategies for inventory inaccuracy in a two-echelon supply chain. European Journal of Operational Research, 221(1), 213-221. doi:10.1016/j.ejor.2012.03.008

47. Zacharewicz, G., Deschamps, J. C., \& Francois, J. (2011). Distributed simulation platform to design advanced RFID based freight transportation systems. Computers in Industry, 62(6), 597-612. 